\title{
The Slo-Niacin Trial: A Randomized Double-Blind Placebo-Controlled Cross- Over Trial of Extended Release Niacin for Phosphate Lowering in Haemodialysis Patients
}

\author{
Ken-Soon Tan ${ }^{1,2,4,5^{*}}$, Deepak L Vardesh ${ }^{3}$, Padma Raman ${ }^{2}$, Jeremy Frazier ${ }^{2}$ and Elizabeth Jarvis ${ }^{1,2}$ \\ ${ }^{1}$ Renal Unit, Logan Hospital, Queensland, Australia \\ ${ }^{2}$ Renal Unit, Princess Alexandra Hospital, Queensland, Australia \\ ${ }^{3}$ Division of Medicine, Logan Hospital, Queensland, Australia \\ ${ }^{4}$ University of Queensland School of Medicine, Australia \\ ${ }^{5}$ Griffith University School of Medicine, Queensland, Australia
}

"Corresponding author: Ken-Soon Tan, Renal Unit, Building 2, Logan Hospital, Corner Armstrong and Loganlea Roads, Meadowbrook, 4131, Queensland, Australia, Tel: + 617-3089-2049/+617-3089-2018; Fax: + 6173089 2042; E-mail: ks_t@hotmail.com

Rec date: Mar 03, 2013, Acc date: Apr 09, 2014, Pub date: Apr 12, 2014

Copyright: (c) 2014 Tan KS, et al. This is an open-access article distributed under the terms of the Creative Commons Attribution License, which permits unrestricted use, distribution, and reproduction in any medium, provided the original author and source are credited.

\begin{abstract}
Aim: Is once daily low dose extended release niacin effective at lowering phosphate?

Background: Serum phosphate levels correlate with mortality in dialysis patients. Current phosphate binders often cause side-effects leading to poor compliance. Niacin has previously been shown to lower serum phosphate in patients with kidney disease. However, at doses previously used ( $\geq 1 \mathrm{~g}$ daily), it is poorly tolerated. Slo-niacin $\circledast$ is a extended release formulation taken once daily.

Methods: The study was a single-centre double-blind placebo-controlled randomised cross-over trial in haemodialysis patients. All patients received both active treatment (500 mg Slo-niacin $₫$ daily) and matching placebo for 8 weeks each with intervening 2 week washout phase. All patients continued usual phosphate binders and Cinacalcet/vitamin D analogues, although no dose adjustments were permitted. Patients were recruited if they were $>18 \mathrm{yo}$, not pregnant and serum phosphate 4 weeks prior to commencement was $\geq 1.8 \mathrm{mmol} / \mathrm{L}$. All gave informed consent.
\end{abstract}

Results: 33 patients were recruited. 1 patient died following emergency cardiac surgery during placebo phase \& 3 patients withdrew (2 niacin, 1 placebo, $p=N S$ ) leaving 29 for analysis. Extended release niacin significantly reduced serum phosphate compared to placebo ( $p<0.0014$, t-test and ANOVA). Mean absolute difference between groups was $-0.35 \mathrm{mmol} / \mathrm{L}(95 \% \mathrm{Cl}-0.62 \mathrm{mmol} / \mathrm{L}$ to $-0.08 \mathrm{mmol} / \mathrm{L})$ in favour of niacin $(\mathrm{p} \sim 0.01$, $\mathrm{t}$-test). Neither treatment altered calcium levels. Extended release niacin was well tolerated apart from early mild flushing which improved with time.

Conclusion: Once daily low dose extended-release niacin is effective at lowering serum phosphate.

Keywords: Haemodialysis; Phosphate binder; Mineral bone disorder

\section{Introduction:}

Hypophosphatemia is a key component of CKD-mineral bone disorder (CKD-MBD) and is common in patients with CKD 5D. In a large prospective cohort study of incident dialysis patients [1], mean serum phosphate was $5.23 \mathrm{mg} / \mathrm{dl}(1.69 \mathrm{mmol} / \mathrm{L})$, subsequently rising to $5.43 \mathrm{mg} / \mathrm{dl}(1.75 \mathrm{mmol} / \mathrm{L})$ over a 6 month period.

In dialysis patients, multiple studies [2-4] have shown a positive correlation between increased serum phosphate levels and (all-cause) mortality risk. Thus, national and international guidelines have emphasised the role of phosphate reduction in this patient group.

Serum phosphate is most effectively lowered using medications. The main groups of medications used are the phosphate binders which bind phosphate in the gut, preventing its absorption. However, current phosphate binders (Calcium based, Lanthanum carbonate, Sevelamer hydrochloride and Aluminium hydroxide) generally present a heavy pill burden as they are taken with food, i.e. generally several times daily. Indeed, Chiu et al [5] showed that Phosphate binders can be responsible for $\sim 50 \%$ of a typical dialysis patient's pill burden. Moreover, these medications generally have gastrointestinal (GI) side effects, and could further compromise oral-intake in patients already susceptible to malnutrition. Not surprisingly, compliance or adherence with these medications is generally poor, only $38 \%$ in Chiu et al's study [5].

Niacin (Nicotinic Acid) and its metabolite Niacinamide (Nicotinamide), both forms of Vitamin B3, have been shown to lower serum phosphate. The postulated mechanism, based on a rat model, is inhibition of the Na-Pi2b sodium-phosphate co-transporter in the gut [6]. This mechanism of action is distinct from current phosphate binders. However, it is unclear whether this is the case in humans, or 
Citation: Tan KS, Vardesh DL, Raman P, Frazier J, Jarvis E (2014) The Slo-Niacin Trial: A Randomized Double-Blind Placebo-Controlled CrossOver Trial of Extended Release Niacin for Phosphate Lowering in Haemodialysis Patients. J Nephrol Ther 4: 157. doi: 10.4172/2161-0959.1000157

Page 2 of 6

indeed in other mammalian species. Furthermore, only Nicotinamide was used in Eto et al's study [6] and Niacin has never been studied directly. Whilst it is tempting to assume that the phosphate lowering effect of Niacin occurs through its metabolite Nicotinamide, this is probably too simplistic, as the metabolism of Niacin to Nicotinamide principally occurs in the liver, which would imply involvement of an enterohepatic circulation. Thus, both metabolites may actually independently inhibit Na-Pi2b. Several clinical trials in humans [7-9] have examined the role of both agents separately in lowering phosphate in dialysis patients although none have directly compared Niacin to Nicotinamide. Furthermore, despite efficacy being demonstrated for both compounds, previous trials have utilised higher doses, increasing the risk of side effects (mainly flushing, in the case of niacin).

Niacin is differentially metabolised through 2 pathways: conjugation which generates metabolites which cause flushing and amidation which generates hepatotoxic metabolites [10-12]. The relative activity through each pathway is governed by rate of absorption from the gut [10]. Immediate release preparations are rapidly absorbed and preferentially undergo conjugation [10]. On the other hand, sustained release preparations are slowly absorbed from the gut, and preferentially undergo amidation [10]. Extended release preparations represent a happy medium between these 2 extremes [10].

Extended release preparations have been shown to be effective at lowering phosphate. Sampathkumar et al. [13] used a $375 \mathrm{mg}$ extended release preparation and achieved a mean reduction in serum phosphate of $>2 \mathrm{mg} / \mathrm{dl}(>0.6 \mathrm{mmol} / \mathrm{L})$. However, this particular preparation is not available outside India and moreover, Sampathkumar et al. [13] employed an open label design.

On the other hand, Slo-niacin (Upsher Smith, MN, USA) is an extended release preparation which is readily available in a range of strengths $(250 \mathrm{mg}, 500 \mathrm{mg}$ and $750 \mathrm{mg}$ ). We postulated that using the $500 \mathrm{mg}$ strength once daily should produce results comparable to those achieved by Sampathkumar et al. [13]

\section{Methods}

Local ethics committee approval was granted (Metro South Human Research Ethics Committee, HREC/10/QPAH/083) and the trial was registered with the Australia and New Zealand clinical trials registry (12611000500954). The study was a single-centre randomized doubleblind placebo-controlled cross-over trial examining the additional phosphate lowering efficacy of extended release Niacin over usual background binders in patients undergoing maintenance haemodialysis at Logan hospital, a secondary care hospital in Queensland, Australia. Thus, each patient acted as their own control. Our primary outcome was change in serum phosphate. The cross-over study design is appropriate for our population as within patient variance for serum phosphate was less than between patient variance (0.02 V 0.30, p<0.05, t-test).

Inclusion criteria were thrice weekly maintenance haemodialysis (in hospital or at home), serum phosphate $>1.8 \mathrm{mmol} / \mathrm{L}$ at the time of recruitment (despite dietitian review and phosphate binder use) and age $>18$ years old at time of recruitment. Exclusion criteria were age $<18$ years old, current pregnancy, likelihood of receiving a renal transplant within 20 weeks of commencing study (currently active on deceased donor list or suitable live donor already found), known allergy to Niacin and concurrent enrolment in another trial of experimental medication.

Our methods were similar to that of Cheng et al. [9] and is summarised in Figure 1.

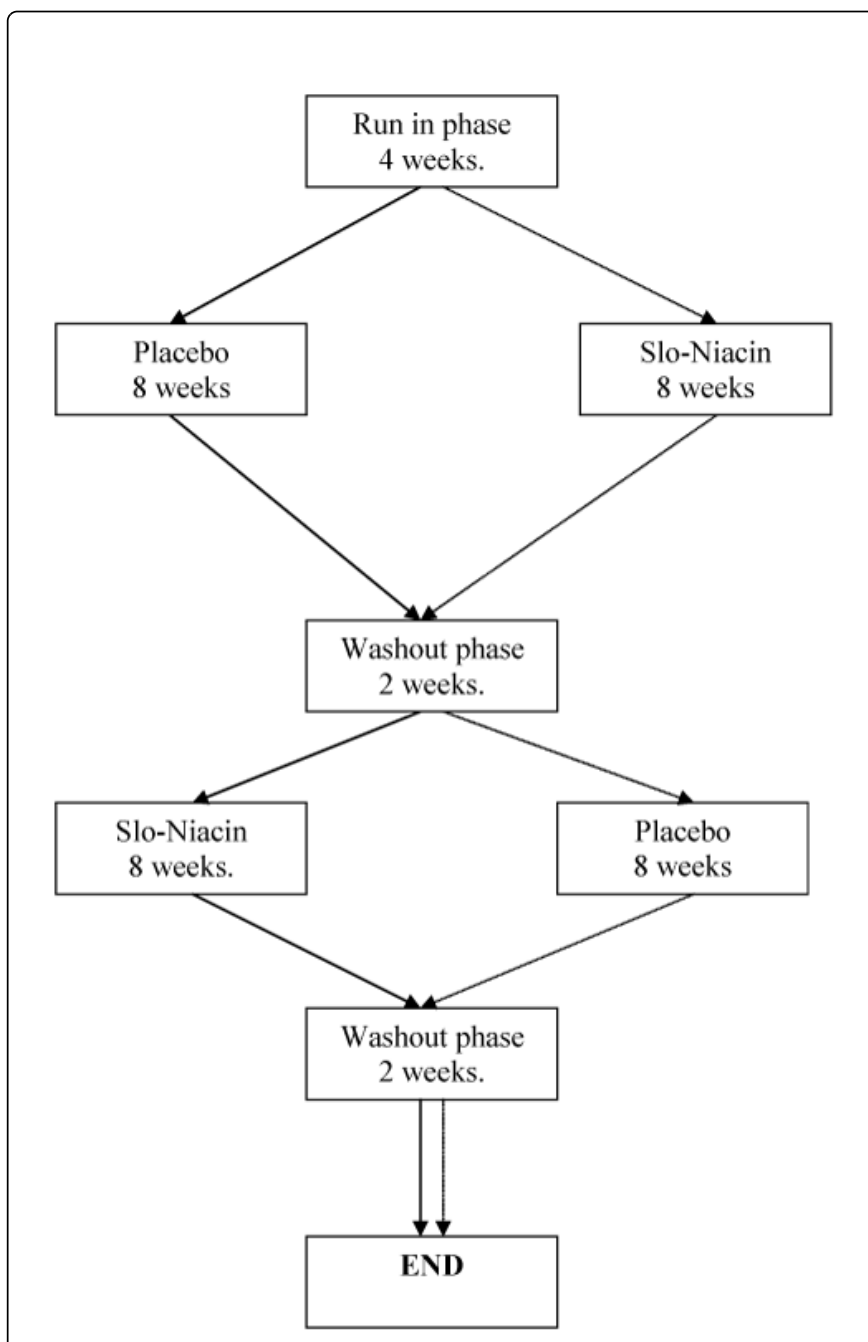

Figure 1: Trial schema

All patients remained on their usual background regimen of phosphate binders, vitamin D analogues and Cinacalcet throughout although no dose adjustment was permitted for the entire duration of the study ( 24 weeks).

All patients in our unit were using high flux dialysers and were on haemodiafiltration. Whilst changes in dialysis prescription were allowed, our patient population was generally resistant to increases in dialysis duration, and in fact this did not occur during the course of the study.

Patients were approached if their serum phosphate was $>1.8$ $\mathrm{mmol} / \mathrm{L}$ on routine monthly bloods, they were already taking conventional phosphate binders and had received dietitian review (standard practice for all dialysis patients in our unit). Those who consented then commenced a 4 week run-in period. They then took either a single tablet of placebo (Richard Stenlake Compounding Chemist, Sydney, Australia) or Slo-niacin ${ }^{\circledR} 500$ mg (Upsher-Smith, 
Citation: Tan KS, Vardesh DL, Raman P, Frazier J, Jarvis E (2014) The Slo-Niacin Trial: A Randomized Double-Blind Placebo-Controlled CrossOver Trial of Extended Release Niacin for Phosphate Lowering in Haemodialysis Patients. J Nephrol Ther 4: 157. doi: 10.4172/2161-0959.1000157

Page 3 of 6

MN, USA) for 8 weeks. A 2 week washout period followed before patients commenced the other treatment for a further 8 weeks. A final 2 week washout period completed the trial.

The trial medication was packed offsite in identical containers by the company which had manufactured the placebo. The computer generated randomisation sequence was also determined offsite by the company which had manufactured the placebo. Patients were allocated to the appropriate sequence in order of recruitment and were supplied with the 8 weeks' worth of pills (56 pills). Results were analysed in blinded fashion by an offsite investigator who had no contact with the trial patients. All costs of the trial medication and the randomisation process were met by the investigators.

Serum calcium, phosphate and liver function were measured every 2 weeks. Patients were withdrawn from the study if their serum Alanine transaminase (ALT) or Aspartate serum transaminase (AST) were newly elevated into the abnormal range during the duration of the study, or any of the values doubled from baseline (if already abnormal at baseline). Parathyroid hormone (PTH) was measured monthly together with usual monthly bloods (full blood count, urea and electrolytes, albumin). All blood tests were collected on the midweek dialysis session. Patients were asked to return the pill containers at the end of each trial phase, regardless of the number of pills remaining. We did not measure lipid profiles as all previous lipid lowering trials involving niacin have used at least double the daily dose we used in this study. In any case, we had not designed the study to examine changes in lipid levels.

We recorded the incidence of flushing, GI disturbance, liver function derangement (as defined above), and thrombocytopenia (defined as new onset platelet count $<100 \times 109 / \mathrm{L}$ ).

\section{Statistics}

Based on the data from previous studies $[9,13]$, we postulated that an effect size of $0.3 \mathrm{mmol} / \mathrm{L}$ difference in serum phosphate between treatments over 8 weeks was both biologically plausible and clinically relevant. Based on data from our unit on the inter-patient variability of serum phosphate over time, our estimated SD was $0.55 \mathrm{mmol} / \mathrm{L}$. Thus, to achieve $80 \%$ power at the $5 \%$ significance level, we required 27 patients. We assumed a drop-out rate of $20 \%$ and aimed to recruit 33 patients.

Continuous data are expressed as either mean and SD or median with IQR as appropriate.

T-test and ANOVA adapted for cross-over trials were used to compare the difference between serum phosphate levels and the difference between serum calcium levels. Test statistics for carry-over effects, treatment effects and period effects were calculated. The model assumptions were tested by calculating both the studentised withinsubject residuals and the studentised between-subject residuals.

McNemar's test (with Yates's correction for continuity) was used to compare number of patients with adverse effects. Fisher's exact test was used to compare the number of study withdrawals.

All statistical analysis was carried out using STATA (Intercooled version 12.1).

\section{Results}

33 patients were recruited over the period 20/6/2012 and 26/7/2012. The last patient completed the trial on 31/10/2012. 17 were randomized to receive Niacin first and 16 were randomized to receive placebo first (Figure 2). 1 patient died and 3 patients withdrew from the study because they experienced side-effects of flushing. All 3 withdrawals occurred within the first week of commencing the first treatment phase. In keeping with analysis of cross-over trials, these 4 patients were excluded from the final analysis.

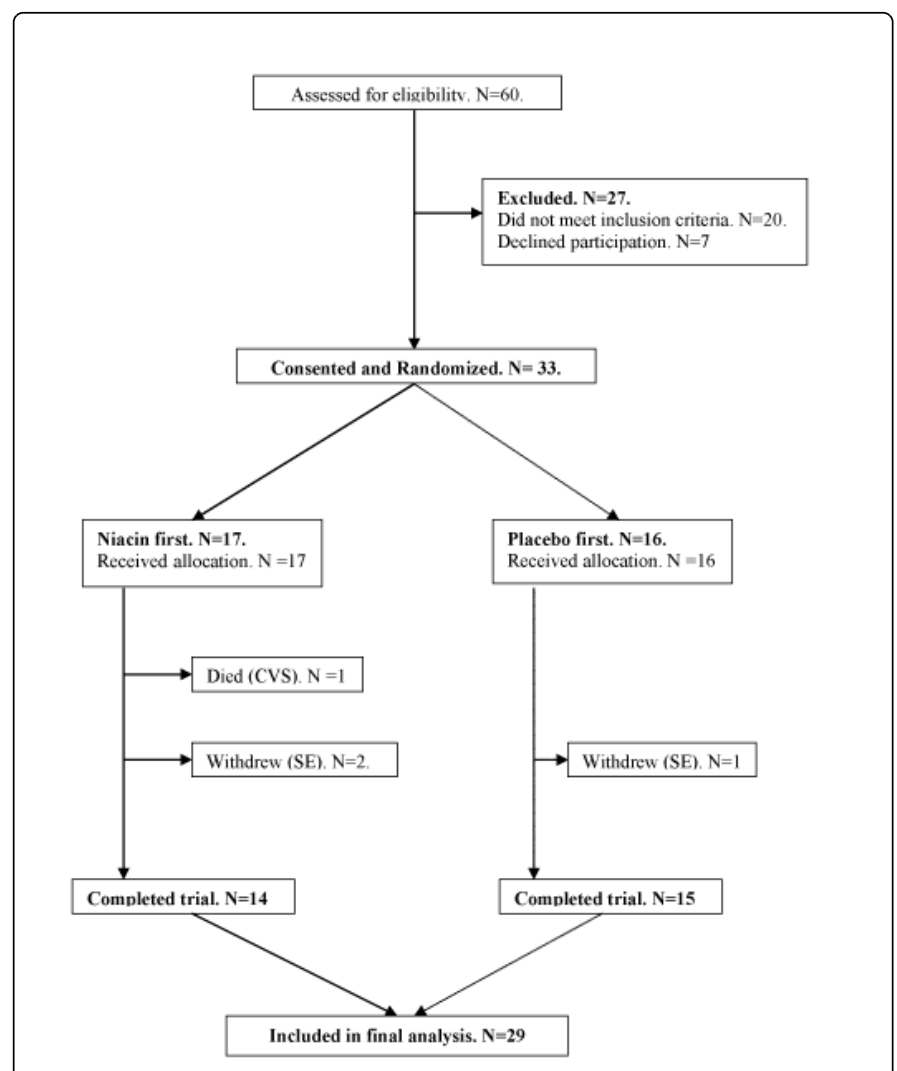

Figure 2: Consort Diagram

The patient who died was a 59 year old female with known coronary artery disease who died following complications of emergency cardiac surgery. She was actually on the placebo at the time of her death. This death was reviewed by the ethics committee who agreed that it was unrelated to trial medication. The 3 patients who withdrew all did so within the $1^{\text {st }} 2$ weeks of the $1^{\text {st }}$ treatment phase. 2 patients were taking extended release Niacin and 1 was taking placebo $(\mathrm{p}=0.6$, Fisher's exact test).

The baseline characteristics of the remaining 29 patients are summarised in Table 1.

\begin{tabular}{|l|l|}
\hline Sex (n, \%) & Male 19 (65.5\%) \\
\hline Age in years (median, IQR). & $60(52-71)$ \\
\hline Race $(\mathrm{n}, \%)$ & Caucasian $19(65.5 \%)$ \\
& ATSI $2(6.9 \%)$ \\
& Pacific Islander $6(20.7 \%)$ \\
& Asian 2 (6.9\%) \\
\hline Aetiology of renal failure $(\mathrm{n}, \%)$ & DM $16(55.2 \%)$ \\
\hline
\end{tabular}


Citation: Tan KS, Vardesh DL, Raman P, Frazier J, Jarvis E (2014) The Slo-Niacin Trial: A Randomized Double-Blind Placebo-Controlled CrossOver Trial of Extended Release Niacin for Phosphate Lowering in Haemodialysis Patients. J Nephrol Ther 4: 157. doi: 10.4172/2161-0959.1000157

Page 4 of 6

\begin{tabular}{|l|l|}
\hline & $\begin{array}{l}\text { GN 6 (20.6\%) } \\
\text { Other 7 (24.1\%) }\end{array}$ \\
\hline Dialysis vintage in months (mean, SD) & $66(59)$ \\
\hline Dialysis Access (n, \%) & $\begin{array}{l}\text { Fistula: } 27(93.1 \%) \\
\text { Graft: } 2(6.9 \%)\end{array}$ \\
\hline $\begin{array}{l}\text { Starting Phosphate in mmol/L (mean, } \\
\text { SD) }\end{array}$ & $1.89(0.42)$ \\
\hline Starting Calcium in mmol/L (mean, SD) & $2.32(0.16)$ \\
\hline Starting PTH in nmol/L (median, IQR) & $24(11-82)$ \\
\hline $\begin{array}{l}\text { Phosphate binder pill burden: median } \\
\text { number of pills per day (IQR) }\end{array}$ & Calcium based: 3 (2-6) \\
\hline Taking Lanthanum (n, \%) & $8(27.6 \%)$ \\
\hline Taking Sevelamer (n, \%) & 14 (48.3\%) \\
\hline Taking Cincacalcet (n, \%) & $15(51.7 \%)$ \\
\hline Taking Calcitriol (n, \%) & 21 (72.4\%) \\
\hline
\end{tabular}

Table 1: Characteristics of included patients

ATSI: Aboriginal/Torres strait islander; Pacific Islander=Maori, Samoan, Tongan, DM: Diabetic nephropathy; GN: Glomerulonephritis.

\section{Baseline phosphate control}

In keeping with the treatment-resistant nature of this patient group, median daily phosphate-binder pill burden was 9, 3 calcium based \& 6 non-calcium based (usually Lanthanum or Sevelamer). There was also a high level of Cinacalcet use (50\%). $10(\sim 1 / 3)$ of patients had previously switched non-calcium based binders (Sevelamer to Lanthanum or vice versa).

\section{Effect on serum phosphate}

Once daily low dose extended release niacin significantly reduced serum phosphate compared to placebo ( $\mathrm{p}=0.0014, \mathrm{t}$-test). The results are plotted as mean \pm SD serum phosphate by time period (Figure 3 ). There was no carry-over effect ( $\mathrm{p}=0.6, \mathrm{t}$-test) or period effect $(\mathrm{p}=0.3, \mathrm{t}$ test). Sensitivity analysis performed using ANOVA gave the same result. Calculation of the studentised within-subject residuals and the studentised between-subject residuals showed that the model assumptions were valid (data not shown).

Figure 3: Mean $( \pm S D)$ serum phosphate level by treatment period and treatment sequence

Mean change in serum phosphate was $-0.23 \mathrm{mmol} / \mathrm{L}$ (SD 0.55) for extended release Niacin versus $+0.12 \mathrm{mmol} / \mathrm{L}$ (SD 0.47) for placebo (Figure 4). Thus, mean absolute difference between groups was -0.35 $\mathrm{mmol} / \mathrm{L}(95 \% \mathrm{CI}-0.62 \mathrm{mmol} / \mathrm{L}$ to $-0.08 \mathrm{mmol} / \mathrm{L})$ in favour of extended release niacin $(\mathrm{p}=0.01, \mathrm{t}$-test $)$.

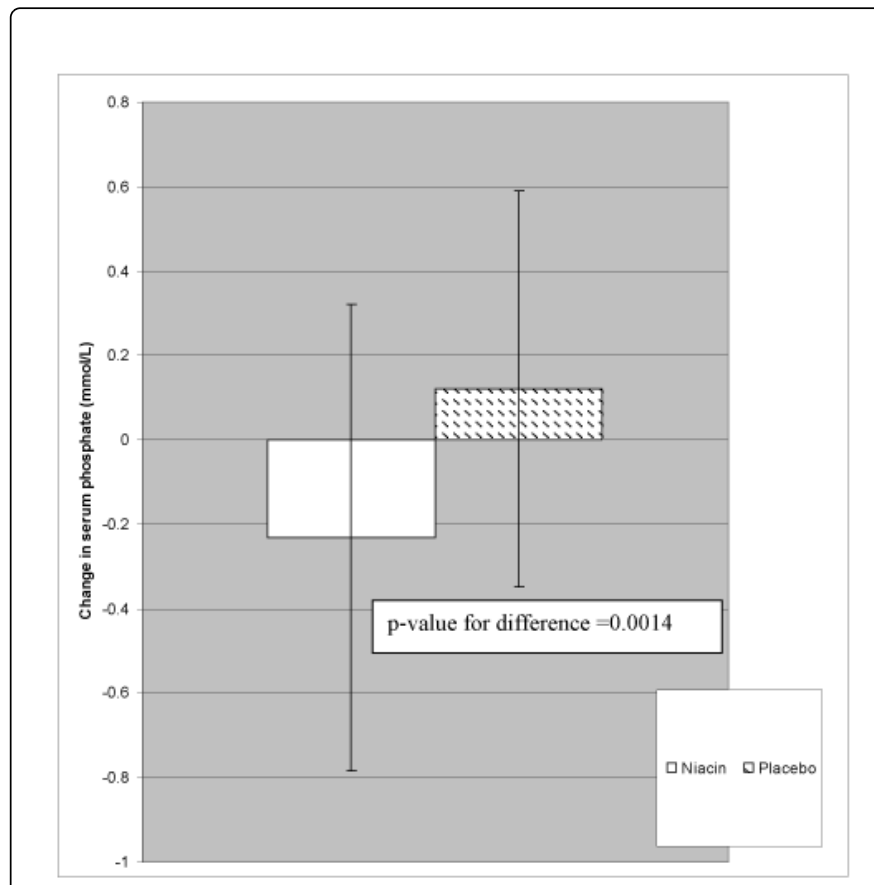

Figure 4: Mean change in serum phosphate $( \pm S D)$ by treatment

\section{Pill counts}

$17 / 29$ patients $(\sim 59 \%)$ returned extended release Niacin pill containers. 3 of these had medication remaining, $\leq 4$ pills in each case. In contrast $19 / 29$ patients $(\sim 66 \%)$ returned placebo pill containers. 4 
Citation: Tan KS, Vardesh DL, Raman P, Frazier J, Jarvis E (2014) The Slo-Niacin Trial: A Randomized Double-Blind Placebo-Controlled CrossOver Trial of Extended Release Niacin for Phosphate Lowering in Haemodialysis Patients. J Nephrol Ther 4: 157. doi: 10.4172/2161-0959.1000157

Page 5 of 6

of these had placebo medication remaining: 1 patient had 1 pill, 1 patient had 2 pills, 1 patient had 12 pills and 1 patient had 15 pills.

\section{Effects on serum calcium}

Calcium levels did not change significantly in either group (data not shown). There was no difference between either group ( $p \sim 0.5$, t-test for treatment effect).

\section{Adverse events}

Apart from the 3 patients who withdrew because of flushing ( 1 of whom was actually taking placebo), 2 other patients complained of flushing for a few hours after taking extended-release niacin $(\mathrm{p}=0.03$, McNemar's test). However, in both cases, this side effect seemed to resolve within the first 3 doses, and both patients completed the study.

None of our patients developed Liver function derangement, GI disturbance or thrombocytopenia

\section{Discussion}

Like previous trials, we also found that Niacin effectively reduces serum phosphate although we have shown that this could be achieved with a fixed low dose of extended-release preparation given once daily. Phosphate reduction occurred soon after commencing treatment and also reversed quickly on cessation of treatment.

We acknowledge that compliance amongst our patient group may have been sub-optimal, thus underestimating treatment effect. Nevertheless, of the 17 patients who returned extended release Niacin pill containers, all patients had taken $>80 \%$ pills. Thus, using a conservative estimate, if all 12 patients who did not return an extended release Niacin pill container are assumed to have taken $<80 \%$ of the pills, then a minimum of $17 / 29$ patients $(\sim 59 \%)$ demonstrated $\geq 80 \%$ compliance with Niacin. Using the same method, only 17 of the 19 patients who returned placebo pill containers had taken $\geq 80 \%$ of the pills. If all 10 patients who did not return pill containers are assumed to have taken $<80 \%$ of the pills, then only $17 / 29$ patients $(\sim 59 \%)$ demonstrated $\geq 80 \%$ compliance with placebo. Notwithstanding, these conservative estimates still exceed Chiu et al's [5] finding that only $38 \%$ of dialysis patients show $\geq 80 \%$ compliance with their prescribed phosphate binders.

In Cheng et al's trial [9] using Nicotinamide, the reduction in serum phosphate overall was $0.79 \mathrm{mg} / \mathrm{dl}(\sim 0.25 \mathrm{mmol} / \mathrm{L})$ although in the subgroup of patients with $\geq 80 \%$ compliance, this rose to $1.17 \mathrm{mg} / \mathrm{dl}$ $(\sim 0.37 \mathrm{mmol} / \mathrm{L})$. This lends support to our suspicion that the results we achieved would be more rather than less impressive if compliance was better.

Notwithstanding, the fact that we found evidence of efficacy using a low fixed dose is in keeping with SampathKumar et al. findings that large doses may not always be necessary [13].

Another limitation of this study is that with the disparate background binder regimens, we could not exclude that the phosphate reduction seen occurred as a consequence of interaction. Neither Lanthanum nor Sevelamer have significant oral absorption. Thus, any interaction is unlikely to be pharmacokinetic. However, compliance with background binder regimen may also actually have varied over the course of the study, although the randomised cross-over nature of this trial should have overcome this.
Our study withdrawal rate of $<10 \%$ is low. Importantly, although flushing still occurred as an uncommon side-effect in patients taking extended release Niacin, this side-effect appeared to resolve spontaneously after the first few doses.

Whilst our trial was still in progress, Aramwit et al. [14] published a double blind randomised placebo controlled trial of another extended release Niacin preparation $\left(\mathrm{Niaspan}^{\circledast}\right)$. In contrast to our study, this study demonstrated that whilst extended release Niacin significantly reduced serum phosphate, the difference between the placebo group and the extended release niacin group was not statistically different. There are important methodological differences between this trial and our trial. Most importantly Aramwit et al. [14] employed a parallel group design. Thus, their study population of 28 (14 per treatment group) was almost certainly not adequately powered to detect a difference between groups (i.e. type 2 error). Secondly, the dose of extended release Niacin was progressively increased (as tolerated) over the course of the treatment period whereas we used a fixed dose throughout. However, the mean reduction in serum phosphate of 1.47 $\mathrm{mg} / \mathrm{dl}(\sim 0.47 \mathrm{mmol} / \mathrm{L})$ was certainly comparable to our study. Interestingly, despite the use of higher doses of Niacin, Aramwit et al. also encountered a low dropout rate of $<10 \%$ [14].

Ahmadi et al. [15] conducted an open-label randomised trial comparing Sevelamer and the immediate release form of Niacin. The authors concluded that Sevelamer had greater serum phosphate lowering effect. However, this conclusion was erroneous, because the difference in phosphate reduction between the 2 groups over the treatment period was in fact not statistically significant $(p=0.3)$ [15]. It is, however, of note that the phosphate reduction of $1.7 \mathrm{mg} / \mathrm{dl}(>0.5$ $\mathrm{mmol} / \mathrm{L}$ ) achieved in the Niacin group over a 1 month period [15] is greater than that achieved in this study and Cheng et al's study [9]. Furthermore, this reduction was achieved with the same total daily dose of Niacin as our study, once again suggesting that low dose therapy may be sufficient. Despite the low dose of Niacin, Ahmadi et al. found that the incidence of significant side effects (mainly flushing) prompting study withdrawal was high (25\%) [15]. Although not adequately powered to examine this phenomenon, the lower incidence of side effects prompting withdrawal $(<10 \%)$ in this study, suggests that extended release Niacin may be better tolerated than the immediate release form used by Ahmadi et al. [15]

None of our patients had hepatotoxicity or GI side effects. We also monitored for thrombocytopoenia, although this side effect has actually only been reported with Nicotinamide rather than Niacin, again lending weight to the possibility that Niacin's phosphate lowering effect may be independent of any metabolism to Nicotinamide. More recently, Jamal et al. [16] published a metaanalysis comparing the effect of calcium and non-calcium based binders on mortality which concluded that non-calcium based binders were associated with a $22 \%$ decrease in all-cause mortality compared to calcium based binders, although cardiovascular mortality was not examined. No double-blind randomised trials involving dialysis patients were included. The authors also noted that in the studies that examined phosphate levels (14 of 18 included studies), there was no difference between the 2 classes, [16] thus the mortality benefit noted could still have been due to an increase in mortality in those taking calcium based binders rather than a true decrease in mortality attributable to non-calcium binders. Whilst there is currently still no good evidence to support a mortality benefit with phosphate reduction, Jamal et al. publication [16] might lead to calcium-neutral phosphate lowering therapies being used first-line. In this regard, cost 
Citation: Tan KS, Vardesh DL, Raman P, Frazier J, Jarvis E (2014) The Slo-Niacin Trial: A Randomized Double-Blind Placebo-Controlled CrossOver Trial of Extended Release Niacin for Phosphate Lowering in Haemodialysis Patients. J Nephrol Ther 4: 157. doi: 10.4172/2161-0959.1000157

Page 6 of 6

may be an issue and it is noteworthy that the cost of Slo-niacin ${ }^{\circledR}$ is low: A $\$ 15$ for 100 tablets of $500 \mathrm{mg}$ compared to $\mathrm{A} \$ 180.95$ for 100 tablets of $800 \mathrm{mg}$ Sevelamer and A\$138.14 for 100 tablets of $750 \mathrm{mg}$ Lanthanum, as of January 2013. Gray et al. [17] had previously shown that PBS subsidization of non-calcium based binders has led to significant increase in use (and cost) of these agents, despite little improvement in serum phosphate control.

\section{Conclusion}

This study shows that once-daily low dose extended release niacin is effective at lowering serum phosphate. We echo Cheng et al's [9] call that a head to head comparison trial with other more conventional phosphate lowering agents is warranted although in this case, trial dosing regimens would have to be carefully devised to reflect the thrice daily regimen typical of other agents. We would additionally suggest that such a study be performed in patients who are early into their dialysis career when the possibility of using less phosphate binders makes the methodology easier.

\section{Acknowledgements:}

The authors gratefully acknowledge the support of Professor Jim Petrie (retired) who initially proposed the idea of the trial and together with the corresponding author, co-funded the costs of placebo manufacture, packaging of the trial medications and generation of the randomization sequence.

No other external funding was received for this trial and the authors declare no conflict of interest.

\section{References}

1. Melamed ML, Eustace JA, Plantinga L, Jaar BG, Fink NE, et al. (2006) Changes in serum calcium, phosphate, and PTH and the risk of death in incident dialysis patients: a longitudinal study. Kidney Int 70: 351-357.

2. Block GA, Klassen PS, Lazarus JM, Ofsthun N, Lowrie EG, et al. (2004) Mineral metabolism, mortality, and morbidity in maintenance hemodialysis. J Am Soc Nephrol 15: 2208-2218.

3. Kestenbaum B, Sampson JN, Rudser KD, Patterson DJ, Seliger SL, et al. (2005) Serum phosphate levels and mortality risk among people with chronic kidney disease. J Am Soc Nephrol 16: 520-528.

4. Rodriguez-Benot A, Martin-Malo A, Alvarez-Lara MA, Rodriguez M, Aljama P (2005) Mild hyperphosphatemia and mortality in hemodialysis patients. Am J Kidney Dis 46: 68-77.
5. Chiu YW, Teitelbaum I, Misra M, de Leon EM, Adzize T, et al. (2009) Pill burden, adherence, hyperphosphatemia, and quality of life in maintenance dialysis patients. Clin J Am Soc Nephrol 4: 1089-1096.

6. Eto N, Miyata Y, Ohno H, Yamashita T (2005) Nicotinamide prevents the development of hyperphosphataemia by suppressing intestinal sodium-dependent phosphate transporter in rats with adenine-induced renal failure. Nephrol Dial Transplant 20: 1378-1384.

7. Takahashi Y, Tanaka A, Nakamura T, Fukuwatari T, Shibata K, et al. (2004) Nicotinamide suppresses hyperphosphatemia in hemodialysis patients. Kidney Int 65: 1099-1104.

8. Müller D, Mehling H, Otto B, Bergmann-Lips R, Luft F, et al. (2007) Niacin lowers serum phosphate and increases HDL cholesterol in dialysis patients. Clin J Am Soc Nephrol 2: 1249-1254.

9. Cheng SC, Young DO, Huang Y, Delmez JA, Coyne DW (2008) A randomized, double-blind, placebo-controlled trial of niacinamide for reduction of phosphorus in hemodialysis patients. Clin J Am Soc Nephrol 3: 1131-1138.

10. Pieper JA (2002) Understanding niacin formulations. Am J Manag Care 8: S308-314.

11. McKenney JM, Proctor JD, Harris S, Chinchili VM (1994) A comparison of the efficacy and toxic effects of sustained- vs. immediate-release niacin in hypercholesterolemic patients. JAMA 271: 672-677.

12. Etchason JA, Miller TD, Squires RW, Allison TG, Gau GT, et al. (1991) Niacin-induced hepatitis: a potential side effect with low-dose timerelease niacin. Mayo Clin Proc 66: 23-28.

13. Sampathkumar K, Selvam M, Sooraj YS, Gowthaman S, Ajeshkumar RN (2006) Extended release nicotinic acid - a novel oral agent for phosphate control. Int Urol Nephrol 38: 171-174.

14. Aramwit P, Srisawadwong R, Supasyndh O (2012) Effectiveness and safety of extended-release nicotinic acid for reducing serum phosphorus in hemodialysis patients. J Nephrol 25: 354-362.

15. Ahmadi F, Shamekhi F, Lessan-Pezeshki M, Khatami MR (2012) Comparison of efficacy of the phosphate binders nicotinic acid and sevelamer hydrochloride in hemodialysis patients. Saudi J Kidney Dis Transpl 23: 934-938.

16. Jamal SA, Vandermeer B, Raggi P, Mendelssohn DC, Chatterley T, et al. (2013) Effect of calcium-based versus non-calcium-based phosphate binders on mortality in patients with chronic kidney disease: an updated systematic review and meta-analysis. Lancet 382: 1268-1277.

17. Gray NA, Krishnasamy R, Vardesh DL, Hollett PR, Anstey CM (2011) Impact of non-traditional phosphate binders and cinacalcet on haemodialysis patient biochemistry, pill burden and cost. Nephrology (Carlton) 16: 688-696. 